\title{
Analysis on the Present Situation and Countermeasures of "Zang Jia Le" Rural Tourism in Ruoergai County
}

\author{
Fengyan Shao \\ Southwest Minzu University, Chengdu, China \\ Email: 1060987581@qq.com
}

How to cite this paper: Shao, F.Y. (2020) Analysis on the Present Situation and Countermeasures of "Zang Jia Le" Rural Tourism in Ruoergai County. Open Access Library Journal, 7: e6936.

https://doi.org/10.4236/oalib.1106936

Received: October 27, 2020

Accepted: November 6, 2020

Published: November 9, 2020

Copyright $\odot 2020$ by author(s) and Open Access Library Inc.

This work is licensed under the Creative Commons Attribution International License (CC BY 4.0).

http://creativecommons.org/licenses/by/4.0/

\section{(c) (i) Open Access}

\begin{abstract}
With the development of industrialization, urbanization and modernization, rural tourism is gradually emerging, developing and growing under the demand of domestic and foreign markets, and people's awareness of holiday leisure and entertainment is gradually increasing, therefore, rural tourism around the country is growing rapidly by virtue of its own advantages, and theme tourism types such as eco-tourism, folk tourism and experience tourism emerge in endlessly. In this paper, by visiting "Zang Jia Le" in Ruoergai County, Aba Prefecture, to experience the service of "Zang Jia Le", and to understand the causes, types and characteristics of the formation of "Zang Jia Le". This paper further analyzes the predicament of the development of "Zang Jia Le" and makes corresponding ideas and countermeasures for its development.
\end{abstract}

\section{Subject Areas \\ Tourism Economy}

\section{Keywords}

Rural Tourism, Zang Jia Le, Cultural Experience

\section{The Development Background of "Zang Jia Le" in Ruoergai County}

Tourism and vacation have become our common way of leisure and entertainment, soothing, stereotyped hotels can no longer meet our leisure needs, what we need more is to integrate with local characteristics and experience the unique local customs and customs. The development of "Zang Jia Le" in Ruoergai 
County, on the one hand, promotes the local economic development, on the other hand, it can well inherit and protect the local characteristic culture.

As the name implies, "Zang Jia Le" is a mode of rural tourism with the reception of residential houses with Tibetan characteristics as the core and the local Tibetan food and beverage as its characteristics. At present, "Zang Jia Le" widely exists in Ruoergai County, Ganzi Prefecture, Tibet, Qinghai and other Tibetan areas, which has become one of the preferred tourism experiences in Tibetan areas, and the scale of "Zang Jia Le" construction is getting larger and larger. The rural tourism of "Zangjiale" in Ruoergai County attracts a large number of tourists by relying on the characteristics of Tibetan folk customs, culture, religion, natural environment and other resources, which changes the single economic structure of local farmers and herdsmen, and provides an effective way to increase economic income. It has injected new vitality into the economic development of the Tibetan areas of Ruoergai County.

\section{The Development Conditions of "Zang Jia Le" in Ruoergai County}

\subsection{Location Conditions}

Ruoergai County, which belongs to Aba Tibetan and Qiang Autonomous Prefecture, is located in the north of Sichuan Province, with an area of 10,436.58 square kilometers. At the end of 2010, the total population of the county was 75,791. Adjacent to Maqu County, Luqu County, Zhuoni County, Diebu County and Neiaba County, Hongyuan County, Songpan County and Jiuzhaigou County in Aba Prefecture, the maximum distance between east and west and north and south is about 150 kilometers. Ruoergai County enjoys the reputation of "the most beautiful alpine wetland grassland in China" and "the hometown of Chinese black-necked cranes". It is known as "the oasis of the plateau of northwest Sichuan" and "heaven in the clouds". On September 25, 2018, Ruoergai County won the honorary title of "2018 e-commerce into rural comprehensive demonstration county" of the Ministry of Commerce [1]. On April 28, 2019, the people's Government of Sichuan Province decided that Ruoergai County would withdraw from the sequence of poor counties ${ }^{1}$.

\subsection{Natural Environment}

Ruoergai is rich in natural resources and pleasant natural scenery, as shown in Figure 1. The author came to Ruoergai and was attracted by the slogan of the county seat. "If the poem is painted Ruoergai", the place with a good name is like a magnificent emerald embedded in the border of northwest Sichuan. The central and western part of the county, with vast grasslands, lush water plants and herds of cattle and sheep, is known as "the oasis of the plateau of northwest Sichuan"; in the east, the mountains are continuous, suitable for agriculture and ${ }^{1}$ Yin Li presided over the 26th executive meeting of the provincial government to approve Pingwu County and other 30 counties to withdraw from the poverty-stricken county sequence. Sichuan Provincial people's Government. 


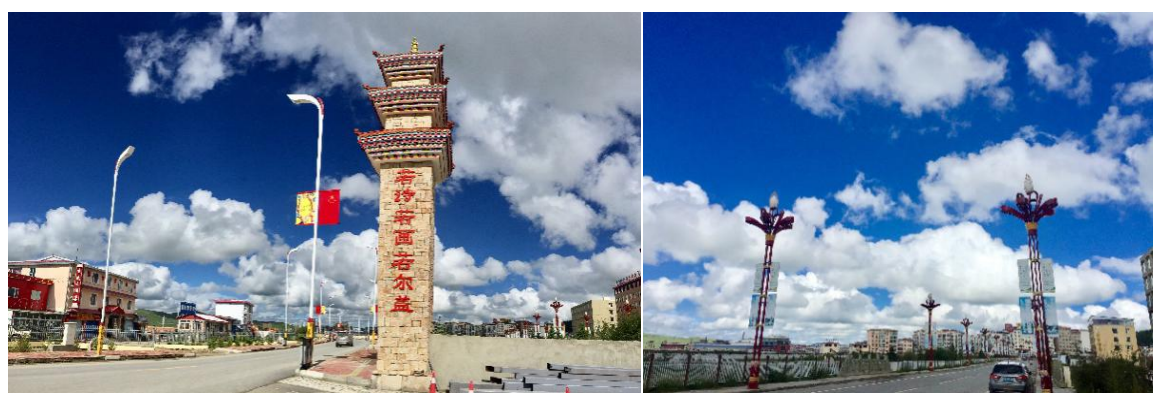

Figure 1. Style and features of Ruoergai county (photo credit: the author).

animal husbandry. Ruoergai County has a vast territory, rich resources and outstanding advantages. On the basis of such rich natural resources, it is an inevitable trend to develop tourism and build "Zang Jia Le" rural tourism.

\subsection{Folk Customs}

Tibetan and Qiang people have lived in Ruoergai for generations, forming their own unique national customs and features. Local clothing culture, food culture, highland barley wine culture and Tibetan folk dance pot village can be refreshing, come to Ruoergai, experience the local unique ethnic customs, but also have a unique charm. Murals and thangka all have strong local and national characteristics; collectors and Qiang village dwellings also have their own flavor, and local people transform their dwellings into accommodation and "Zang Jia Le" for tourists, which brings a unique experience for tourists, such as immersive experience of Tibetan and Qiang culture, tasting Tibetan and Qiang cuisine, and so on.

Ruoergai has a strong religious culture and a long history, and famous religious temples can be found everywhere, such as Maiwa Temple, Daza Temple, Namogerdi Temple and so on. Ruoergai is also a red tourist scenic spot. The world-famous 25,000 Li long March left valuable revolutionary wealth and rich red tourism and cultural resources in the Ruoergai area. Ruoergai is the most dangerous place during the Red Army's long March. By developing the mode of red tourism, we can not only carry out patriotic propaganda and education, but also promote the economic development of the local society.

\section{Analysis of the Present Situation of "Zang Jia Le" in Ruoergai County}

Generally speaking, the tourism industry in Ruoergai region shows a good trend of development. In the past three years, the total income of tourism and the number of tourists received in Ruoergai County have gradually increased, and the development of "Zang Jia Le" in Ruoergai County has also achieved good results, but if we take a closer look at the operation and management of individual "Zang Jia Le", there are still many problems.

For example, the visited Ruoergai County, "Ruoshuiwan Zang Jia Le" as shown in Figure 2, is located in the county seat, with convenient transportation 


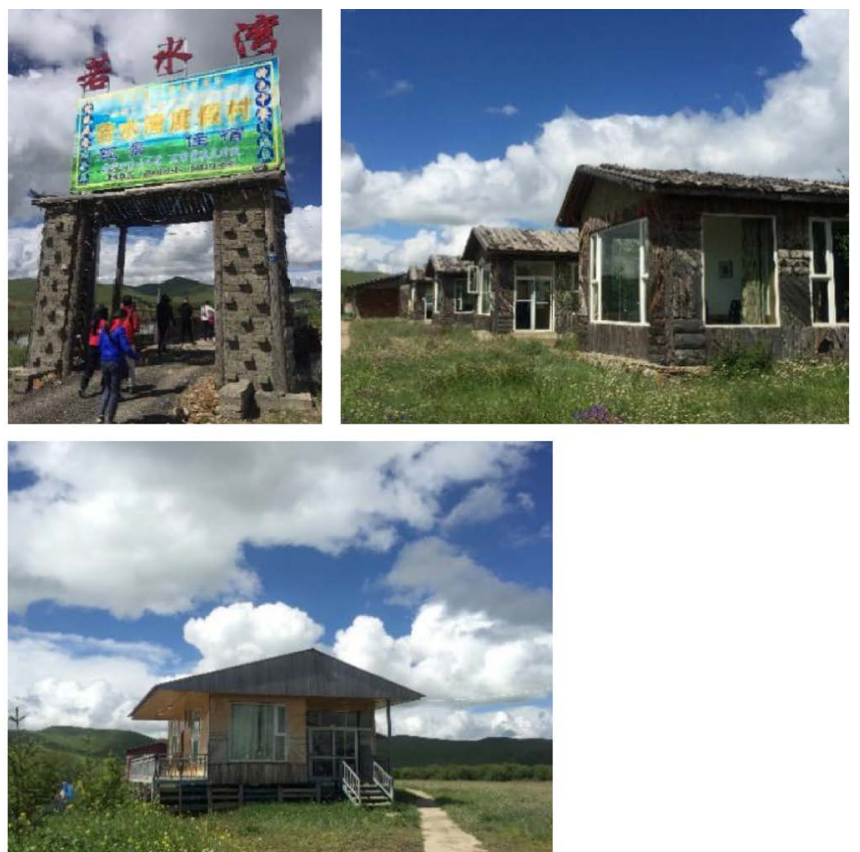

Figure 2. Ruo Shui Wan Zang Jia Le (photo credit: the author).

and good geographical location, which is mainly characterized by the traditional cuisine of collectors, and the surrounding environment is beautiful. however, there are still some areas for improvement in its internal space design, operation and management. Ruoshuiwan Zang Jia Le has four kinds of theme dining space, as shown in Figure 2, the overall architectural style is unified, but the correlation of the four spaces is not high, is the four relatively large private rooms in Ruoshuiwan, each small space is also lack of thematic design, just to meet the basic catering needs. The division of outdoor spatial structure is not clear, the guide system is not complete, and the whole courtyard area is large, but for example, where is the eating space, where is the public toilet, where is the landscape area, there is no clear division and guide. These problems are the common problems of most "Zang Jia Le" in environmental design. In terms of operation and management, more "Zang Jia Le" does not have a strict model, and most of them are the original mode of operation and service model, and the service quality of the general mobilization operation of the whole family is not as good as that of residential accommodation in cities or farmhouse music in some rural areas. The basic service facilities are also relatively simple.

\section{The Problems Existing in the Development of "Zang Jia Le" in Ruoergai County}

\subsection{The National Cultural Characteristics Are Not Obvious}

The biggest reason for rural tourists to leave their place of residence to travel to rural areas is that there are differences between urban and rural areas in terms of natural landscape, natural environment, social economy, life style, cultural characteristics and so on. Therefore, it determines the status of traditional rural 
culture as the most important material and focuses on the production and combination of tourism products [2]. The development of rural tourism in Ruoergai "Zang Jia Le" is mainly based on Tibetan culture, but other local cultures have not been reasonably utilized and are only in the preliminary exploration stage and need to be further explored and developed. For example, some of the "collector's music" has a performance meaning to some cultural resources, while losing the value that culture should have reflected.

\subsection{The Market Positioning Is Vague}

The demanders of "Zang Jia Le" rural tourism are not only local residents, but also foreign tourists, which should not only meet the actual needs of local residents, but also meet the special needs of foreign tourists' experience. Therefore, "Zang Jia Le" should have the correct market orientation and promotion strategy.

At present, the operator of "collector's music" in Ruoergai County is not very clear about its market positioning. In order to enrich its service mode and function, some "collector's music" have appeared, such as blindly spending a lot of money to improve hardware facilities. Excessive decoration of the building appearance and interior, the purchase of modern entertainment experience (karaoke, video games, etc.), which will lead to tourists to ethnic areas, rural tourism experience is not good. It makes its will to pursue the original ecological vernacular architecture and natural ecological landscape go against the vision. In addition, "Zang Jia Le" does not have a full understanding of the tourists received, does not have a sufficient understanding of the tourist source market, and mistakenly brings all urban residents into the scope of the rural tourist source market, which will lead to the majority of "Zang Jia Le" receiving individual tourists, while group tourists such as tour groups are less likely to stay with collectors. However, there are still a lot of "collector music" only do group reception, this business model is too single, the development of "collector music" will go up and down with the operation of travel agencies.

\subsection{Weak Infrastructure Construction}

Most of the initiators of "Zang Jia Le" are local farmers and herdsmen, who lack professional ability in infrastructure construction, and most of them imitate excellent cases to decorate their own "Zang Jia Le". Improving infrastructure construction is an important embodiment of effectively protecting the basic rights and interests of farmers. There is a common phenomenon of awareness of weak foundation in the development of "Zang Jia Le" in Ruoergai area affected by traffic and logistics in Tibetan areas, many infrastructures are difficult to meet the play experience of all urban residents. Specifically reflected in the scale of the reception needs to be improved, there are widespread problems such as poor facilities, poor clean and sanitary conditions, and even non-standard services caused by language communication barriers. A lot of "Zang Jia Le" is a fami- 
ly-based development model, which presents an unimaginable feeling to tourists due to the influence of family living habits in Tibetan areas.

\subsection{Lack of Financial Support}

There must be financial support to improve the external environment and competitiveness of rural tourism. And Ruoergai County is limited by the relevant financial support of the government, even if there is a government support fund, until the layers of approval, there are very few farmers and herdsmen. "Zang Jia Le" is mainly self-management, farmers and herdsmen have their own financial constraints, if they want to expand the scale or improve conditions, they need to accumulate a lot of funds, at this time, it is necessary to introduce foreign enterprises to invest. According to the current development situation, the problem of funds is the biggest obstacle to the development of "Zang Jia Le" rural tourism.

\subsection{Single Type of Products to Be Sold}

In the rural tourism of "Zang Jia Le", the sales performance of the local characteristic products is single. Many "Zang Jia Le" only offer the sale of special food in Tibetan areas, and some sell handicrafts or creative products of local traditional culture and religion. However, due to the restrictions of transportation and logistics in Tibetan areas, the purchasing channels of "Zang Jia Le" are narrow, and the producers of products are not all local products. This will bring tourists a way for "Zang Jia Le" rural tourism to sell profits rather than spread characteristic culture. Most consumers pay more attention to the intention when choosing tourism products, while ignoring the cultural value of the goods themselves. "Collector Music" operators have this mentality and deal with the choice of tourist souvenirs without too much consideration of the value of the products.

\subsection{Weak Brand Awareness}

Brand is an important symbol of product quality, for those "collector music" with high brand value, its operation mode and management are relatively more scientific and reasonable. At present, there are still many problems in the process of brand positioning of "Zang Jia Le" in Ruoergai County, such as only providing local farm food, single form of room arrangement, and so on. In this way, the products and services provided by "Zang Jia Le" can not meet the needs of every consumer. Therefore, "Zang Jia Le" should reposition the brand and formulate a reasonable marketing side according to the market demand and the actual situation.

\section{Ideas and Suggestions on the Development of "Zang Jia Le" in Ruoergai County}

\subsection{Principles of Development}

Highlight Tibetan culture as the highlight. Ruoergai is an important part of the "Ando Tibetan Cultural Zone" of the three major regions of Tibetan culture. 
There are not only Amdo Tibetan culture and long religious culture with unique national and local characteristics, but also Red Army long March culture and two very different regional cultures of agriculture and animal husbandry, which inspire the people of all ethnic groups in the county to unite and struggle. It is one of the country's 30 red tourism boutique routes and one of the 100 classic scenic spots ${ }^{2}$. The "Zang Jia Le" rural tourism in Ruoergai County should highlight the Tibetan culture in Aba Prefecture. On the one hand, the integration of culture adds the cultural heritage of rural tourism products and projects, and enhances the added value of tourism products and projects; on the other hand, it brings different cultural experiences to tourists, which can enhance tourists' awareness of local culture.

To pay attention to the experience of rural tourism as the starting point. The so-called experience means that people spend a period of time in an intrinsically personalized way and get a series of memorable events from it. After the service is personalized, it becomes memorable and becomes an experience [3]. Therefore, experience is to create unforgettable memories and experiences. Although they seem illusory on the surface, they are of great commercial value. The development of "Zang Jia Le" provides tourists with the project experience of living in Tibetan houses, eating Tibetan family banquets, and appreciating traditional Tibetan clothing and art, so that tourists can experience a true portrayal of the life of farmers and herdsmen in the Tibetan area of Ruoergai County, Aba Prefecture, in order to obtain the spiritual satisfaction brought by tourism.

The goal is to improve the service. The rural tourism of "Zang Jia Le" in Aba Prefecture should aim to improve the service characteristics and quality, establish brand awareness, and increase the weight to win in the competition with good word-of-mouth. In the process of upgrading the service, we can also increase the diversification of the service. For example, "Collector's Music" can increase the sale of local-style tourist souvenirs. Unlike the point of sale of special products, the owner of "Collector's Music" can create a small workshop in a certain space, make their own tourist souvenirs and join the teaching experience program, so that tourists can have a different experience. And can personally weave, fabricate and sell many suggested local cultural and creative products, tourists can take their own creative products as a souvenir. The tourist souvenirs sold in "Collector's Music" can also be displayed in front of tourists in the form of residential decoration and placed in every corner of "Collector's Music". Consumers can negotiate with folk owners to buy when they see it.

\subsection{Development Proposals}

Create Tibetan cultural tourism with local characteristics and launch themes rich in local historical and cultural characteristics. Set up the theme "Collector's Music", launch characteristic restaurants and guest rooms, go deep into the national

${ }^{2}$ The office of the people's government of Ruoergai county, the portal of the people's government of Ruoergai county. 
cultural experience. According to the surrounding environment and folk customs, the operators of "collector's music" can integrate into the design of folk environment and enhance the experience effect of tourists. Enrich the internal and external environment design of "Zang Jia Le" and highlight the cultural characteristics of the design. Fully understand the local natural environment and cultural resources symbols, the use of national characteristics of architectural decoration patterns, cultural elements into the "Zang Jia Le" environmental design, enrich the type and number of house decoration. The combination of traditional and modern, the integration of new architectural decoration materials, the use of new construction technology, on the basis of the traditional national architecture, enrich the appearance of the building and increase the dining and living experience of tourists. In ethnic minority areas, not only feel the unique local customs and culture, but also do not lose the modern consumer demand.

Find the right direction of market development. With the diversification of society, culture and economy, cultural motivation has become an important factor for rural tourists to produce rural tourism motivation. The market positioning of rural tourism should start with the differences of rural tourism destinations and cover the regions and categories with the greatest differences on the basis of considering the location conditions. Ruoergai County "Zang Jia Le" rural tourism should find the right direction of market development, one is to clearly understand and give full play to its own advantages, and the other is to understand and meet the needs of tourists. In view of this, the "Zang Jia Le" rural tourism in Ruoergai County should pay attention to the development and utilization of Tibetan culture and create more culturally valuable service systems and tourism products and projects.

Strengthen the assistance of the government. The development of ethnic minority areas is inseparable from the strong support of the government, which plays an important role in the economic construction and social development of ethnic minority areas. According to the findings of the World Tourism Organization, in the process of developing tourism, the government should at least have four functions: travel coordination, legislation, planning and investment, and at least achieve the following five basic objectives: 1) Satisfy the right to leisure and vacation; 2) Travel services for residents; 3) Promote the development and construction of all fields of tourism; 4) Engage in social and cultural development; 5) The protection of nature and the environment are in harmony and symbiosis [4]. With the development of "Zang Jia Le" rural tourism in Ruoergai area, the local government needs to bring the management of rural tourism into the administrative functions of the government and formulate relevant management measures for "Zang Jia Le" rural tourism, make clear their respective positions and responsibilities in this development.

\section{Summary}

The countryside and the city complement each other. With the national policy 
on tourism and the support of rural development, the development of "Zang Jia Le" rural tourism is bound to evolve. With the popularity of the Internet and the diversification of modern tourism needs, the cause of "Zang Jia Le" rural tourism in Ruoergai region needs to re-recognize its own development future, carry out professional development planning and infrastructure construction and design, and the combination of traditional and modern. The combination of culture and nature and the combination of history and the future are all innovations in the development of "Zang Jia Le" rural tourism. The problems such as improving the experience of tourism "collector's music" and improving the management mode of "collector's music" are still worthy of further consideration and practiced by "collector's music" operators.

Some of the problems pointed out in this paper are only some insights given after personal experience combined with excellent cases. The development of "Zang Jia Le" and farm music can not only promote the economic development of local villagers, but also the current trend of tourism development, and find problems. Get the corresponding outcome strategy, hoping to bring meaningful reference value for the development of “Zang Jia Le” in Ruoergai County.

\section{Acknowledgements}

This study was awarded the Graduate Innovation Project of Southwest Minzu University (No. CX2019SZ03) support.

\section{Conflicts of Interest}

The author declares no conflicts of interest regarding the publication of this paper.

\section{References}

[1] Ministry of Commerce of China (2018) Electronic Commerce Will Be Included in the List of Rural Comprehensive Demonstration Counties in 2018.

[2] Wang, W.W. (2012) Study on the Development of Rural Tourism of "Zangjiale" in Ganzi Tibetan Autonomous Prefecture. Master's Thesis, Central University for Nationalities, Beijing.

[3] Pine, J. and Gilmore, J. (2002) Experience Economy. Machinery Industry Press, Beijing.

[4] Kuang, L. (2001) Centralization or Decentralization: The Governments Are in a Dilemma in Developing Tourism Industry. Tourism Tribune, 16, 23-26. http://d.wanfangdata.com.cn/periodical/lyxk200102005 